\title{
Adaptation of an Apple Sooty Blotch and Flyspeck Warning System for the Upper Midwest United States
}

\author{
K. B. Duttweiler and M. L. Gleason, Department of Plant Pathology, Iowa State University, Ames 50011; \\ P. M. Dixon, Department of Statistics, Iowa State University, Ames 50011; T. B. Sutton, Department of Plant Pa- \\ thology, North Carolina State University, Raleigh 27695; P. S. McManus, Department of Plant Pathology, Univer- \\ sity of Wisconsin, Madison 53706; and J. E. B. A. Monteiro, Department of Exact Sciences, ESALQ, University of \\ São Paulo, Piracicaba, SP, Brazil
}

\begin{abstract}
Duttweiler, K. B., Gleason, M. L., Dixon, P. M., Sutton, T. B., McManus, P. S., and Monteiro, J. E. B. A. 2008. Adaptation of an apple sooty blotch and flyspeck warning system for the Upper Midwest United States. Plant Dis. 92:1215-1222.

A warning system for sooty blotch and flyspeck (SBFS) of apple, developed in the southeastern United States, uses cumulative hours of leaf wetness duration (LWD) to predict the timing of the first appearance of signs. In the Upper Midwest United States, however, this warning system has resulted in sporadic disease control failures. The purpose of the present study was to determine whether the warning system's algorithm could be modified to provide more reliable assessment of SBFS risk. Hourly LWD, rainfall, relative humidity (RH), and temperature data were collected from orchards in Iowa, North Carolina, and Wisconsin in 2005 and 2006. Timing of the first appearance of SBFS signs was determined by weekly scouting. Preliminary analysis using scatterplots and boxplots suggested that cumulative hours of $\mathrm{RH} \geq 97 \%$ could be a useful predictor of SBFS appearance. Receiver operating characteristic curve analysis was used to compare the predictive performance of cumulative LWD and cumulative hours of RH $\geq 97 \%$. Cumulative hours of $\mathrm{RH} \geq 97 \%$ was a more conservative and accurate predictor than cumulative LWD for 15 site years in the Upper Midwest, but not for four site years in North Carolina. Performance of the SBFS warning system in the Upper Midwest and climatically similar regions may be improved if cumulative hours of $\mathrm{RH} \geq 97 \%$ were substituted for cumulative LWD to predict the first appearance of SBFS.
\end{abstract}

Additional keywords: disease forecasting, microclimate, ROC analysis

Sooty blotch and flyspeck (SBFS) is a disease complex of apple (Malus $\times$ domestica Borkh.) caused by more than 30 species of fungi in humid regions worldwide $(2,10)$. Apples with SBFS develop dark blemishes that prevent their fresh market sale, resulting in revenue loss as high as $90 \%$ (5,36). Postharvest desiccation is more rapid for SBFS-infested apples than for noncolonized fruit $(8,31)$. In the Upper Midwest United States, colonies of SBFS fungi begin to appear on apples during the middle to late growing season. SBFS incidence and severity are greater, and signs appear earlier, when weather conditions are relatively moist during fruit development (36).

Conventional calendar-based fungicide spray programs, consisting of fungicide applications every 10 to 14 days from petal fall until harvest (12), do not consider the impact of environmental conditions on

Corresponding author: M. L. Gleason

E-mail: mgleason@iastate.edu

Accepted for publication 28 April 2008.

doi:10.1094/PDIS-92-8-1215

(C) 2008 The American Phytopathological Society disease risk and therefore may result in over-application of fungicides (6). Disease-warning systems have been developed to help growers control SBFS in a more cost-effective and environmentally safe manner. A system developed to control flyspeck in New York, based on the residual activity of fungicides, uses both rainfall and leaf wetness duration (LWD) as inputs $(25,36)$. The Brown-Sutton-Hartman system, developed in North Carolina and refined in Kentucky, predicts timing of the first appearance of SBFS based on accumulated hours of LWD (6). The warning system is designed to delay the secondcover fungicide spray until $175 \mathrm{~h}$ of LWD have accumulated since the first-cover fungicide spray (14).

In field experiments and on-farm trials, the Brown-Sutton-Hartman warning system saved an average of two fungicide sprays compared to the conventional schedule $(1,30)$. However, trials in the Upper Midwest (Iowa [IA], Illinois [IL], and Wisconsin [WI]) resulted in sporadic control failures; i.e., significantly higher incidence of SBFS occurred in orchard blocks in which the warning system was used than in blocks in which the calendarbased fungicide-spray schedule was used (1). Growers are unlikely to adopt the warning system if it entails an increased risk of disease, since SBFS damage to a crop can cost far more than the savings associated with reduced fungicide spraying $(7,34)$. Analysis of the control failures revealed no consistent association with risk factors such as inadequate pruning, lowvolume spray applications, or delayed response to the warning system's spray advisories $(8,36)$.

Another possible cause for these failures could be climatic differences between the southeastern United States, where the warning system was developed, and the Upper Midwest. When warning systems developed in one climatic region are imported to other regions, modification of the system's algorithms is often needed to better fit the climate of the new region $(19,27,29)$. The objectives of this study were to determine the ability of weather variables to predict timing of the appearance of SBFS in the Upper Midwest, and to investigate whether modification of the Brown-Sutton-Hartman warning system could increase the system's reliability in this region.

\section{MATERIALS AND METHODS}

Locations. Apple orchards with a history of SBFS in IA, NC, and WI were monitored during the 2005 and 2006 growing seasons (Table 1). Cultural management, block age, geographic features, and vegetative surroundings varied among orchard sites. Study plots consisted of three to five adjacent, mature, semidwarf (height 4 to $5 \mathrm{~m}$, width 3 to $4 \mathrm{~m}$ ) trees in a single row in each orchard. DMI fungicides, which have little activity against SBFS (12), were used to control springtime diseases (primarily apple scab and cedar-apple rust), and additional fungicide applications were withheld after the scheduled first-cover spray (approximately 10 days after petal fall).

Data collection. Air temperature $\left( \pm 1^{\circ} \mathrm{F}\right)$, relative humidity $([\mathrm{RH}] \pm 3 \% \mathrm{RH})$, rainfall $( \pm 2 \%$ rain), and LWD were recorded hourly with WatchDog Plant Disease Weather Stations (Spectrum Technologies, Plainfield, IL). Prior to placement in the field, flat, nonpainted, printed-circuit LWD sensors were calibrated by checking that the highest LW value was recorded when the sensor was 
wrapped in water-saturated paper towel. Temperature and RH sensors were checked by observing indoor readings for at least 6 h. Leaf wetness sensors were placed at approximately $1.5-\mathrm{m}$ height within the tree canopy, facing north, with an inclination angle of $45^{\circ}$ to horizontal. For six of the site years, weather data were collected from the date of scheduled first-cover fungicide spray until the first appearance of SBFS. For the remaining 13 site years, weather data collection extended from the date of the first-cover spray until 1 to 6 weeks after SBFS appeared.

Missing temperature, $\mathrm{RH}$, or rainfall data due to sensor failure were estimated from nearby weather stations. In NC, missing LWD data were estimated with deWit leaf wetness meters (Instrumentenfabrick IFG deWit, Rhoden, the Netherlands) located within the same orchards as the study plots. In IA and WI, missing LWD data were estimated using an algorithm based on dew point deficit (11). Briefly, dew point deficit estimates a wetness event based on the difference between ambient temperature and the temperatures at dew onset and dew dryoff (11). LWD measurements were used to empirically fit average temperature thresholds that corresponded to dew onset and dryoff in apple orchards. The most accurate correlations were obtained with dew point deficit thresholds of $1.0^{\circ} \mathrm{C}$ for dew onset and $2.7^{\circ} \mathrm{C}$ for dew dryoff. Therefore, the first hour during which dew point deficit was $\leq 1.0^{\circ} \mathrm{C}$ was assumed to initiate a wet period, and subsequent hours were considered wet until the dew point deficit was $\geq 2.7^{\circ} \mathrm{C}$. These thresholds were used to estimate and replace missing LWD data. Approximately $12 \%$ of wetness data were estimated by deWit sensors or the dew point deficit algorithm rather than measured.

Observations of disease. The date of first appearance of SBFS was determined by scouting weekly for SBFS signs. Scouting involved visually noting the presence or absence of SBFS colonies on approximately 40 apples arbitrarily chosen from three trees at each study site. Date of first appearance of SBFS signs was assumed to

Table 1. Location of orchards, apple cultivar(s), and year(s) for which data were collected to investigate the performance of sooty blotch and flyspeck warning systems

\begin{tabular}{lllll}
\hline State & City & Coordinates & Cultivar(s) & Year(s) \\
\hline IA & Adel & $41^{\circ} 34^{\prime} \mathrm{N} 94^{\circ} 05^{\prime} \mathrm{W}$ & GoldRush & 2005,2006 \\
IA & Cambridge & $41^{\circ} 52^{\prime} \mathrm{N} 93^{\circ} 28^{\prime} \mathrm{W}$ & Golden Delicious & 2005,2006 \\
IA & Fort Dodge & $42^{\circ} 33^{\prime} \mathrm{N} 94^{\circ} 11^{\prime} \mathrm{W}$ & Golden Delicious & 2005,2006 \\
IA & Gilbert & $42^{\circ} 06^{\prime} \mathrm{N} 93^{\circ} 35^{\prime} \mathrm{W}$ & $\begin{array}{l}\text { Golden Delicious, } \\
\text { Jonathan }\end{array}$ \\
& & & Goo6 \\
IA & Iowa Falls & $42^{\circ} 31^{\prime} \mathrm{N} 93^{\circ} 12^{\prime} \mathrm{W}$ & Golden Delicious & 2005,2006 \\
IA & Jefferson & $41^{\circ} 59^{\prime} \mathrm{N} 94^{\circ} 24^{\prime} \mathrm{W}$ & Golden Delicious & 2005 \\
IA & Nevada & $41^{\circ} 55^{\prime} \mathrm{N} 93^{\circ} 27^{\prime} \mathrm{W}$ & Golden Delicious & 2005,2006 \\
WI & Fitchburg & $42^{\circ} 57^{\prime} \mathrm{N} 89^{\circ} 28^{\prime} \mathrm{W}$ & Jonee & 2006 \\
WI & Madison & $43^{\circ} 04^{\prime} \mathrm{N} 89^{\circ} 24^{\prime} \mathrm{W}$ & Golden Delicious & 2006 \\
WI & Richland Center & $43^{\circ} 20^{\prime} \mathrm{N} 90^{\circ} 23^{\prime} \mathrm{W}$ & Golden Delicious & 2005 \\
NC & Clayton & $35^{\circ} 39^{\prime} \mathrm{N} 78^{\circ} 27^{\prime} \mathrm{W}$ & Golden Delicious & 2005,2006 \\
NC & Fletcher & $35^{\circ} 25^{\prime} \mathrm{N} 82^{\circ} 30^{\prime} \mathrm{W}$ & Golden Delicious & 2005,2006 \\
\hline
\end{tabular}

be the first date on which signs were noted on any of the surveyed apples.

Scatterplot and boxplot analysis. Scatterplots were used to visually assess relationships between weather variables and the time of appearance of first SBFS signs. Weather variables monitored, beginning approximately 10 days after petal fall, included: maximum, minimum, and average daily temperature; cumulative degree days (minimum and maximum threshold of 15 and $30^{\circ} \mathrm{C}$, respectively); rainfall frequency and amount; cumulative hours of LWD and of high RH (thresholds of 80, $85,87,90,95$, and 97\%); and combinations of rainfall, cumulative hours of LWD, and cumulative hours of high RH. Cumulative LWD excluded periods of $<4 \mathrm{~h}$, which reflects the minimum wet period required for establishment of some SBFS fungi (6). At least two consecutive dry hours were required to end an LWD period (3), whereas single hours that were measured as dry but occurred between wet hours were scored as wet. Hours of high $\mathrm{RH}$ were accumulated using the same decision rules as for LWD, except that the hours accumulated were those equaling or exceeding the RH threshold value. The 4-h minimum rule, based on observations that at least $4 \mathrm{~h}$ of wetting were required for germination and/or mycelial growth of the flyspeck species Zygophiala jamaicensis (24), was developed and field validated by Brown and Sutton (6). The number of days from application of the first-cover fungicide spray until the first appearance of SBFS signs was graphed as a function of weather variables. Weather variables exhibiting clustering on scatterplots were identified as potential predictors. It was assumed that data points from an ideal predictor would form a vertical line, indicating that the risk of SBFS appearance was related to a single value of the variable that could be used subsequently as a threshold to trigger a fungicide spray recommendation.

In order to be a useful predictor, an algorithm must be able to warn growers when the appearance of the first signs of SBFS is imminent. Therefore, weather inputs must be able to predict the risk of

1216 Plant Disease /Vol. 92 No. 8
SBFS for each day of the growing season. Accordingly, each day of each site year was assigned to one of two categories depending on whether SBFS was present or absent. Boxplots were generated for weather variables with predictive potential, as indicated by scatterplots, and used to investigate the degree of separation between the two categories (SBFS present or absent) for each weather variable.

Receiver operating characteristic curve analysis. Predictive ability of weather variables was also compared using receiver operating characteristic (ROC) curve analysis. ROC curve analysis is a statistical method that evaluates and compares the performance of diagnostic tests $(17,34)$. The accuracy of a predictor is assessed with regard to four possible test outcomes: true positive (test predicts disease and disease is present); true negative (test predicts no disease and disease is absent); false positive (test predicts disease but disease is absent); and false negative (test predicts no disease but disease is present). A ROC curve graphs the true positive rate as a function of the false positive rate at all possible decision thresholds of the predictor variable $(23,37)$. Area under the ROC curve (AUROC) is used to compare the performance of different predictors; the accuracy of a predictor increases as the value of AUROC approaches one, whereas a value of 0.50 indicates no greater predictive ability than chance (34,35).

Weather variables were evaluated for their ability to predict a threshold occurring 7 days before first appearance of SBFS signs. The 7-day decision rule was adopted in order to provide sufficient time for a grower to apply fungicides and to account for variability in the exact date of SBFS appearance. Therefore, ROC curve analysis was performed to indicate how accurately a weather variable classified days as occurring either before or after 7 days prior to first recorded appearance of SBFS signs. ROC curves plotted the proportion of days correctly classified to occur after this threshold (true positives) against the proportion of days incorrectly classified to occur after the threshold (false positives) for all values of the weather variable. Receiver operating characteristic curve analysis was performed using SAS (SAS Institute, Cary, NC) and Excel (Microsoft, Redmond, WA). To investigate differences due to geographic region, the Upper Midwest (IA and WI) datasets were analyzed with and without the NC datasets, which were also analyzed independently.

Different predictors were compared using a bootstrapping algorithm that accounted for the high correlations among the cumulative variables used to develop the models (22). Usual bootstrapping algorithms assume observations are independent and resample individual observations

- 
with replacement. Because of the correlations among observations within a site year, we resampled the 19 site years. If a site year was selected, all observations from that site year were included in the bootstrap sample. The area under the ROC curve and the difference in AUROC was calculated for each of the two predictors being compared. Bootstrapping of ROC curves and paired $t$ tests were performed in R (R Foundation for Statistical Computing, Vienna, Austria).

An action threshold value was determined for the weather variables that had predictive potential. Thresholds that reduced false positives were considered to be less conservative, whereas those that reduced false negatives were considered to be more conservative. It was decided that the threshold must be conservative, since the cost of false-negative outcomes (loss of crop value owing to downgraded fruit) can greatly exceed the cost of false-positive outcomes (increased fungicide sprays). For the Upper Midwest, therefore, false negatives were arbitrarily allowed to occur in only one of the 15 site years, whereas a larger number of false positives was permitted.

Performance of predictors was evaluated by comparing the accuracy (defined as the total number of true positives and true negatives divided by the total number of outcomes) and incidence of true positives, true negatives, false positives, and false negatives. Performance of predictors for each site year was evaluated by calculating the difference between the actual threshold day (i.e., the 7th day before first appearance of SBFS signs) and the threshold day predicted by weather variables. Optimal predictions were defined as those that occurred within 7 days before the actual threshold day. Predictions prior to 7 days before the actual threshold were scored as false positives, whereas those occurring later were scored as false negatives. The number of extra fungicide sprays entailed by each false positive outcome was estimated for each orchard year, under the assumption that a conventional calendarbased spray program would specify making applications every 2 weeks after the first-cover spray (10). As defined, optimal predictions never led to excessive fungicide sprays.

\section{RESULTS}

For the Upper Midwest (IA and WI), scatterplots indicated that cumulative hours of high RH had the greatest potential as a predictor of the timing of first appearance of SBFS signs. Scatterplots also indicated that LWD had greater potential as a predictor than any of the rainfall and temperature variables, but less potential than RH. The greatest clustering of independent values to a vertical line was observed when a threshold of $\mathrm{RH} \geq 97 \%$ was used (Fig. 1). Boxplots also indicated that cumulative
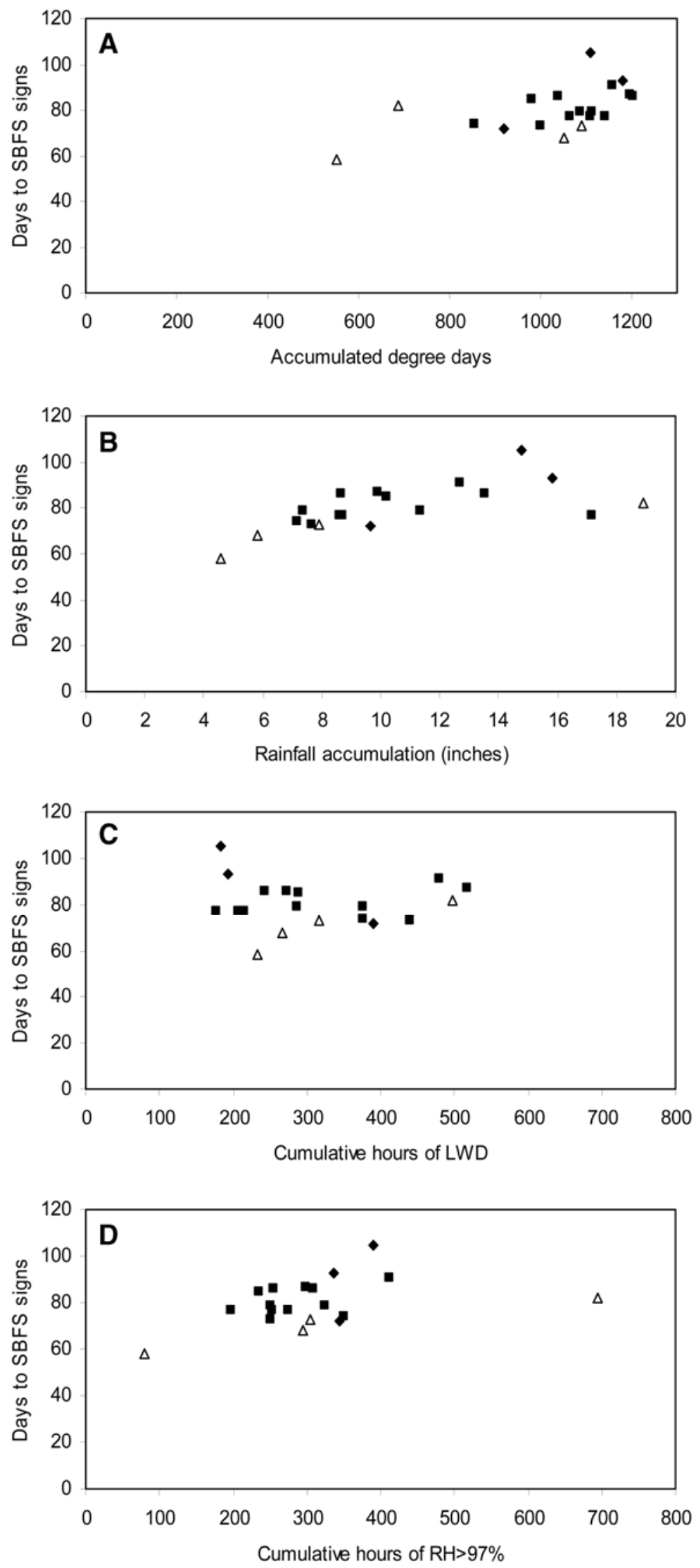

Fig. 1. Scatterplots of time (days) from the first-cover fungicide spray until sooty blotch and flyspeck (SBFS) signs first appeared, as a function of A, temperature, $\mathbf{B}$, rainfall, $\mathbf{C}$, leaf wetness duration, and $\mathbf{D}$, relative humidity. The symbol $\mathbf{r e p r e s e n t s}$ orchards in Iowa, $\checkmark$ represents orchards in Wisconsin, and $\triangle$ represents orchards in North Carolina. The degree of lateral clustering was assumed to be proportional to the predictive potential of weather variables. 
hours of $\mathrm{RH} \geq 97 \%$ resulted in a greater degree of separation of non-SBFS and SBFS groups than LWD (Fig. 2).

The AUROC based on data from the Upper Midwest was significantly greater $(P<0.0001)$ for cumulative hours of $\mathrm{RH} \geq$ 97\% (0.98) than LWD (0.93) (Fig. 3). The action threshold was determined to be 192 cumulative hours of $\mathrm{RH} \geq 97 \%$, as $>1$ false negative outcome occurred in Upper Midwest orchards at higher cumulative LWD values.

Comparison of the predictive performance of LWD using the 175-h threshold and $\mathrm{RH} \geq 97 \%$ using the 192-h threshold (Table 2 and Fig. 4) confirmed that $\mathrm{RH} \geq$ 97\% had the greatest predictive potential for the Upper Midwest. Accuracy was greater, and fewer false negatives and false positives were observed, for cumulative hours of $\mathrm{RH} \geq 97 \%$ than for cumulative
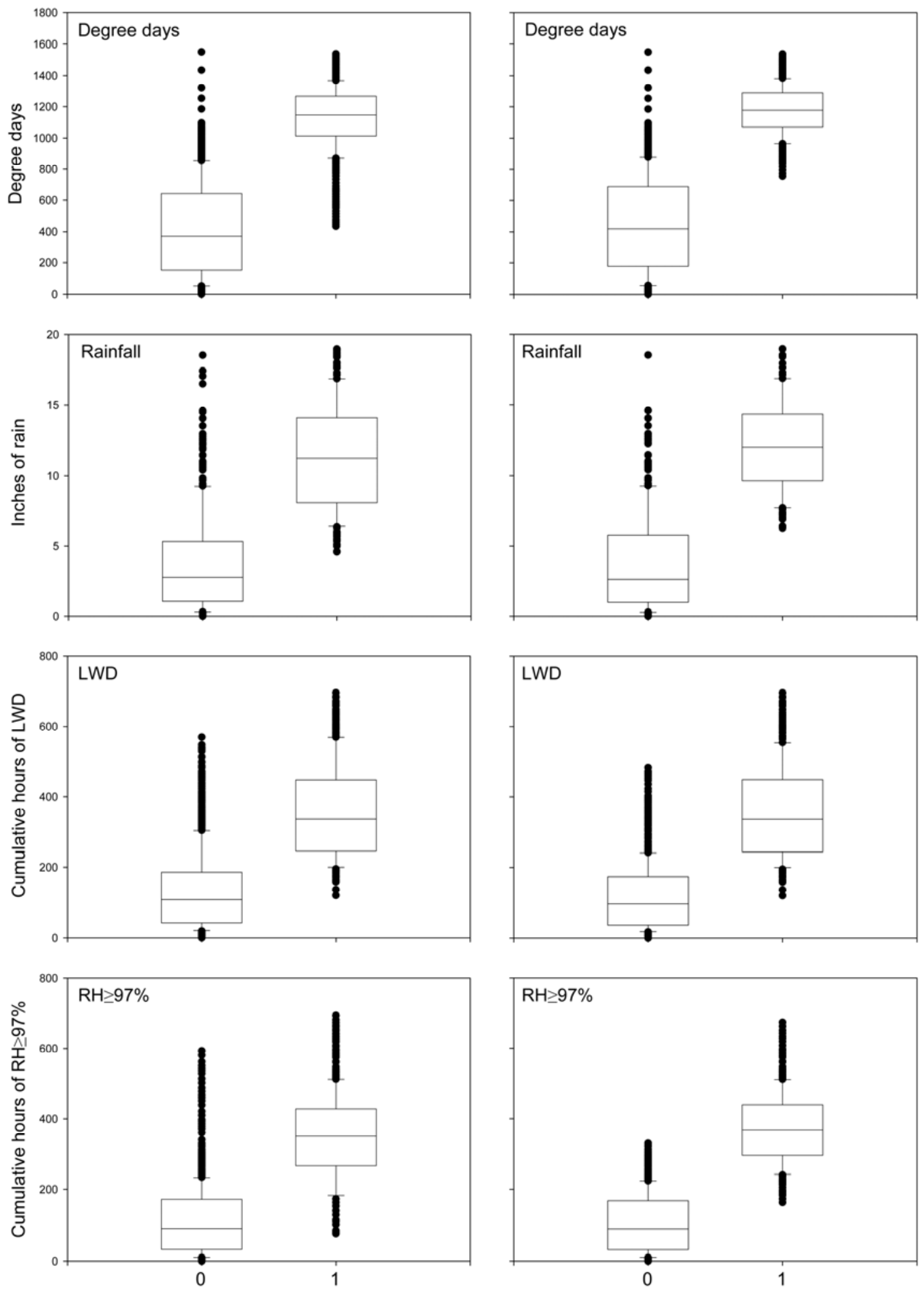

Fig. 2. Boxplots of four weather variables tested as potential predictors of the timing of appearance of sooty blotch and flyspeck (SBFS) signs. Boxplots on the right include all 19 site years (including four from North Carolina), whereas boxplots on the left include only the 15 Upper Midwest site years. Each box represents the distribution of weather variables on days before (0) and after (1) SBFS appeared. The extent of vertical separation of the two boxes was assumed to be proportional to the potential of the weather variable to differentiate between no-risk and risk periods for SBFS. 
hours of LWD. Among the 15 Upper Midwest site years, false negatives occurred in three site years using LWD compared to one using cumulative hours of $\mathrm{RH} \geq 97 \%$ (Fig. 4). Optimal predictions occurred in two and five Upper Midwest site years for LWD and RH $\geq 97 \%$, respectively. Estimated number of extra fungicide sprays per Upper Midwest orchard averaged one fewer for cumulative hours of $\mathrm{RH} \geq 97 \%$ than for cumulative hours of LWD.

When analyses were applied to all 19 site years, including the four site years in $\mathrm{NC}$, differences in predictive potential between the weather variables were reduced. Boxplots were more difficult to differentiate (Fig. 2), and there was no significant difference $(P=0.5868)$ between AUROCs of cumulative LWD (0.93) and cumulative hours of $\mathrm{RH} \geq 97 \%$ (0.92) (Fig. 3). While the overall prediction accuracy of the weather variables differed by only $1 \%$, cumulative hours of $\mathrm{RH} \geq 97 \%$ appeared to be a less conservative predictor (with higher incidence of false negatives and lower incidence of false positives) than LWD when considering all 19 site years (Table 2).

Analysis of the four NC orchard site years determined cumulative hours of LWD as the most accurate predictor of SBFS for NC (Table 2). Cumulative hours of $\mathrm{RH} \geq 97 \%$ had essentially no predictive potential (AUROC $=0.54)$ compared to cumulative hours of LWD (AUROC = 0.93).

\section{DISCUSSION}

The results suggest that the BrownSutton-Hartman warning system, which is based on cumulative hours of LWD, may need to be modified for adaptation to the Upper Midwest and climatically similar regions. In IA and WI, hourly accumulation of $\mathrm{RH} \geq 97 \%$ was both a more accurate and more conservative predictor than LWD of the date of first appearance of SBFS on apples. It was estimated that more fungicide sprays would be saved, and fewer would be applied too late, when using cumulative hours of $\mathrm{RH} \geq 97 \%$ rather than cumulative LWD as inputs to the warning system.

In 12 of 28 previous field trials in the Upper Midwest, the Brown-SuttonHartman warning system resulted in higher incidence of SBFS than observed when using the conventional system of biweekly fungicide sprays (1). Similarly, in two site years in Upper Midwest orchards during the present study, the first signs of SBFS appeared before LWD had reached the 175-h threshold. These observations suggest that occurrences of SBFS control failure in the Upper Midwest may have resulted from inability of LWD to provide a consistently reliable action threshold for disease suppression. In contrast, results from NC confirmed superiority of the LWD model in the Southeast United
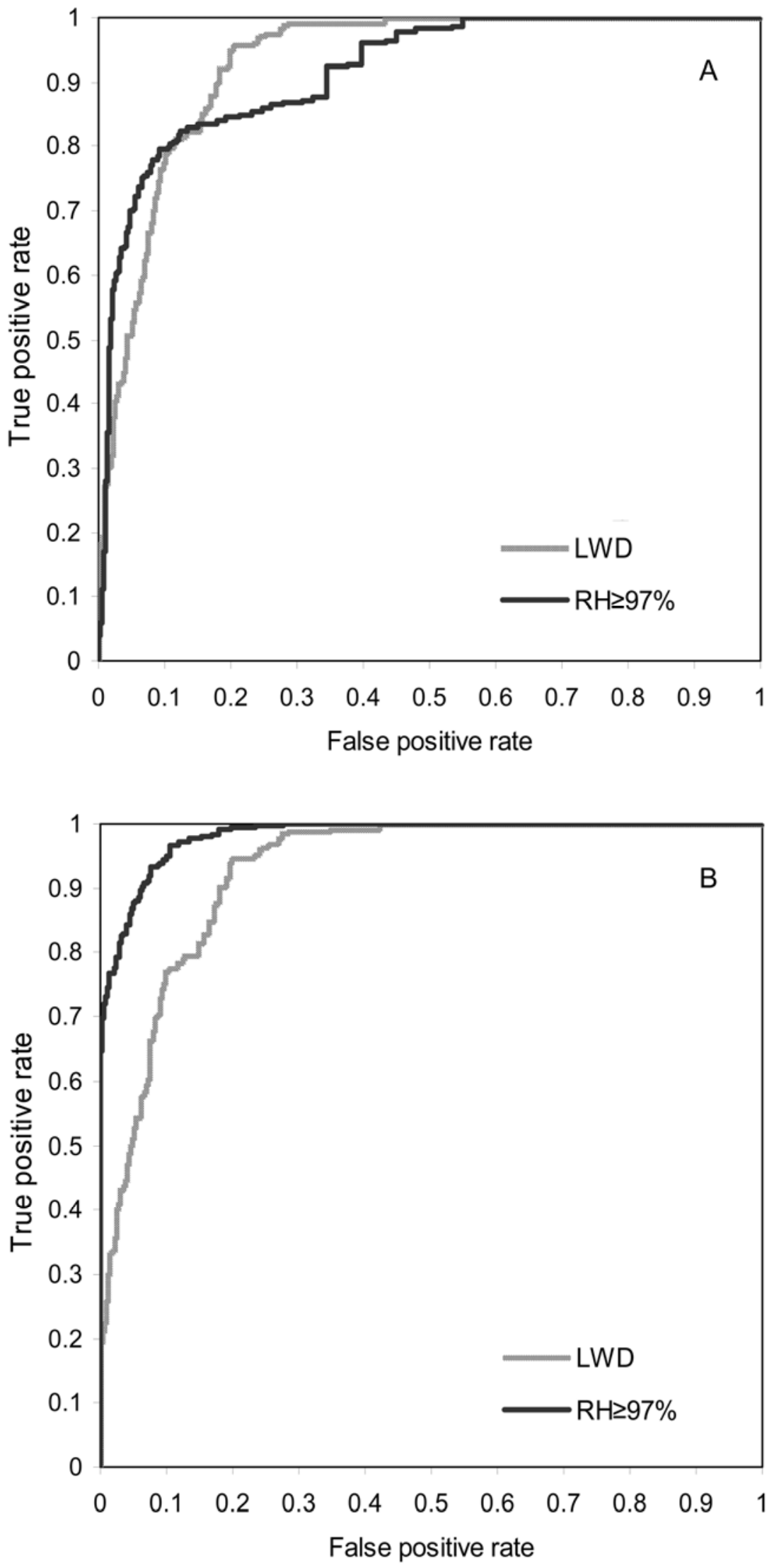

Fig. 3. Receiver operating characteristic (ROC) curves of cumulative hours of leaf wetness duration (LWD) and relative humidity (RH) $\geq 97 \%$ as predictors of timing of the first appearance of sooty blotch and flyspeck (SBFS) signs on apples. A, For all 19 site years, area under the ROC curve (AUROC) for cumulative hours of LWD and RH $\geq 97 \%$ was 0.93 and 0.92 , respectively $(P=0.5868)$ (accuracy of a predictor increases as the value of AUROC approaches one). B, For 15 site years in the Upper Midwest (IA and WI), AUROC for cumulative hours of LWD and RH $\geq 97 \%$ was 0.93 and 0.98 , respectively $(P<0.0001)$. 
States, as cumulative hours of LWD was a better predictor of the first appearance of SBFS than cumulative hours of RH.

There is a biometeorological rationale for the differential performance of the LWD-based warning system in the Upper Midwest compared to the Southeast, where the Brown-Sutton-Hartman system was developed. In the Upper Midwest, substantial spatial heterogeneity of LWD measurements within the canopies of semidwarf apple trees has been documented $(3,4,28)$. Leaf wetness duration measurements varied significantly even among several sen- sors placed at $1.5-\mathrm{m}$ height within the canopy of the same tree (3). This spatial variability was much greater for days when dew was the only source of wetness than on days when rainfall occurred (4). Approximately two-thirds of wet hours in apple tree canopies are caused by dew in the Upper Midwest (18). In the applegrowing region of western $\mathrm{NC}$, in contrast, approximately $70 \%$ of wet hours are associated with rainfall (T. B. Sutton and K. B. Duttweiler, unpublished data). Therefore, spatial heterogeneity of within-canopy LWD measurements is likely to be much

Table 2. Performance of cumulative hours of leaf wetness duration (LWD) and relative humidity (RH) $\geq 97 \%$ as predictors of a fungicide-spray threshold occurring 7 days before first sooty blotch and flyspeck signs appear ${ }^{\mathrm{x}}$

\begin{tabular}{|c|c|c|c|c|c|c|}
\hline & \multicolumn{6}{|c|}{ Predictor performance $^{y}$} \\
\hline & \multicolumn{2}{|c|}{ All site years } & \multicolumn{2}{|c|}{ IA and WI site years } & \multicolumn{2}{|c|}{ NC site years } \\
\hline & LWD & $\mathbf{R H} \geq 97 \%$ & LWD & $\mathbf{R H} \geq 97 \%$ & LWD & $\mathbf{R H} \geq \mathbf{9 7 \%}$ \\
\hline Accuracy ${ }^{z}$ & 81 & 82 & 81 & 87 & 81 & 62 \\
\hline True positives & 97 & 84 & 96 & 98 & 100 & 24 \\
\hline True negatives & 76 & 82 & 76 & 83 & 76 & 77 \\
\hline False positives & 24 & 18 & 24 & 17 & 24 & 23 \\
\hline False negatives & 3 & 16 & 4 & 2 & 0 & 76 \\
\hline
\end{tabular}

$\mathrm{x}$ Each day in an orchard year represents an observation; there were a total of 1,877 days for all 19 site years, including 1,531 days for the 15 Upper Midwest site years and 346 days for the North Carolina site years.

y Performance is calculated as percentage of observations.

${ }^{z}$ Accuracy $=$ total of true positives and true negatives divided by total number of observations.

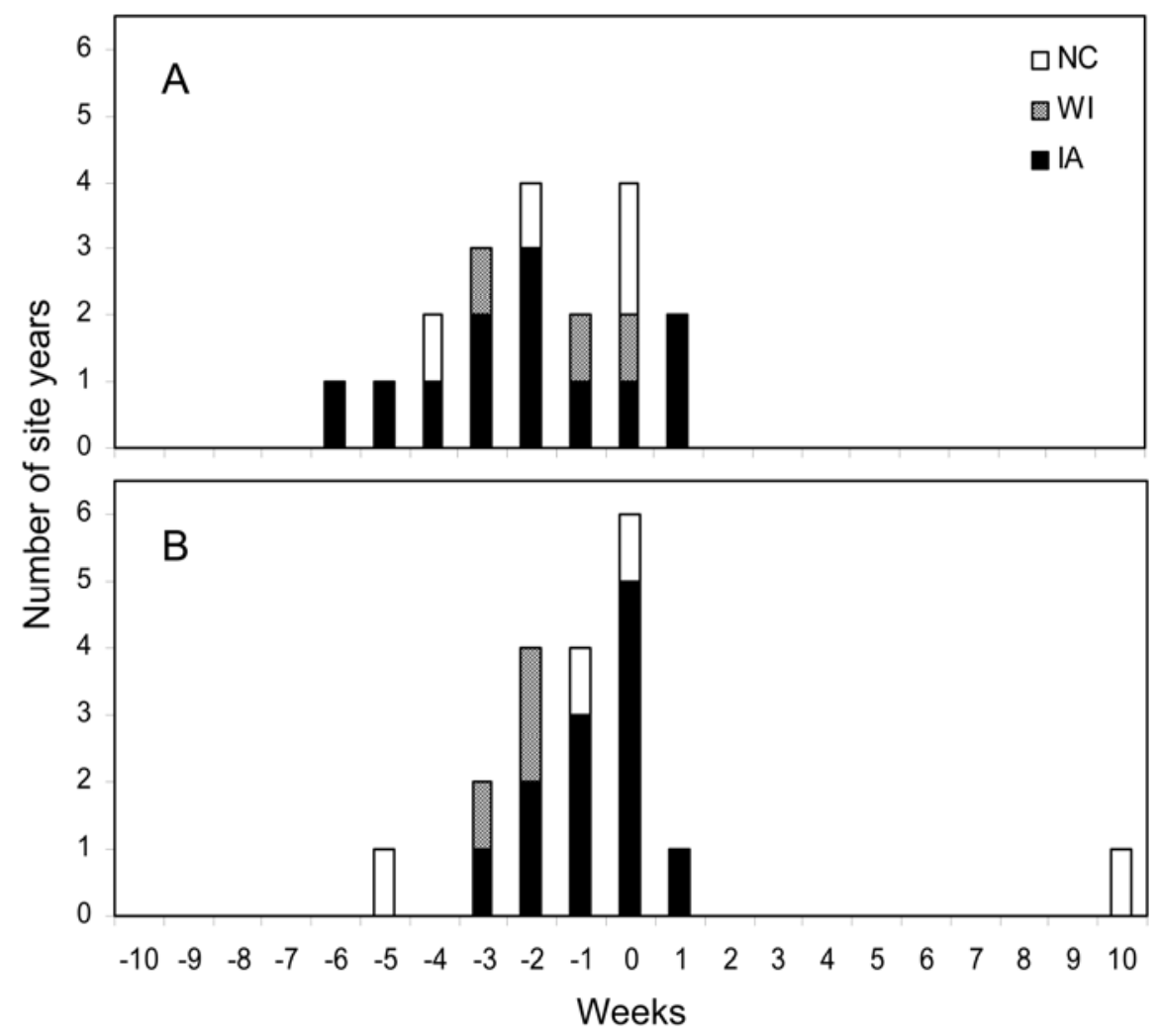

Fig. 4. Difference between the actual sooty blotch and flyspeck (SBFS) threshold day (7 days before the first appearance of SBFS) and the fungicide-spray-threshold day predicted by A, cumulative hours of leaf wetness duration (LWD) and $\mathbf{B}$, cumulative hours of relative humidity (RH) $\geq 97 \%$ for each site year in the study in Iowa (IA), Wisconsin (WI), and North Carolina (NC). Week 0 represents optimal predictions (occurring within 1 week before the actual threshold day). Negative values represent false positives (spray threshold reached too early), whereas positive values represent false negatives (spray threshold reached too late).

more pronounced, and consequently to exert a greater impact on warning system performance, in the Upper Midwest than in the Southeast. The present report is the first to confirm the impact of spatial heterogeneity of within-canopy LWD measurements on performance of a diseasewarning system. Our findings suggest that within-canopy variability in LWD measurements should be a concern when developing and implementing disease-warning systems for apples or other large-canopy crops, particularly in climates in which dew is the predominant source of wet hours.

In order to accurately measure LWD in apple orchards, it has been recommended to place several wetness sensors within the canopy (16). However, this is frequently impractical for growers due to cost and labor limitations. Therefore, LWD of an orchard is commonly measured by a single sensor, which can lead to substantial overor underestimation of LWD in the Upper Midwest (4). In contrast, RH within the canopy of an orchard can be measured relatively accurately with a single sensor, since it is far less subject to within-canopy variability than LWD (16). Unlike LWD, which is a measurement of liquid water, $\mathrm{RH}$ is a measurement of water vapor. The physical nature of water in the form of vapor is less influenced by leaf area, plant architecture, arrangement of plants in the field, and crop height than liquid water. Air, which is constantly moving, homogenizes the gaseous water throughout an apple orchard, thereby leading to similar measurements of RH regardless of sensor placement (32). Relative humidity has been used in other empirically derived warning systems, such as those for apple scab and potato late blight, as an indicator of wetness within a crop canopy (26). Additional challenges of LWD measurement include the lack of an accepted calibration standard and the fact that results can vary considerably depending on sensor type, deployment angle, compass orientation, and whether or not sensors are painted $(13,16,20)$.

Two levels of RH tested, 95 and 97\%, overlapped the range of accuracy of $\mathrm{RH}$ measurement in our sensors $( \pm 3 \%)$. Although there were no significant differences between the scatterplots, boxplots, and predictive accuracy of the two RH measurements, cumulative hours of $\mathrm{RH} \geq 97 \%$ was chosen because it resulted in the fewest extra fungicide sprays (resulting from false positive outcomes) (K. B. Duttweiler, unpublished data). Since a goal of the warning system was to provide the most efficient disease control, reduction of extra fungicide sprays justified the use of cumulative hours of $\mathrm{RH} \geq 97 \%$ over $\mathrm{RH} \geq 95 \%$, even though the two thresholds may not be accurately differentiated by our RH sensors.

Empirically derived disease-warning systems are often optimized to the region 
where they were developed and therefore may not be appropriate for adoption in other regions. For example, three imported fire blight models (MARYBLYT 4.3 and Cougarblight 98C developed in the United States, and BIS95 developed in England) performed poorly in Israel compared to a locally developed model (29). A hypothesized reason for the failures was that the imported models were developed in moist regions in which temperature was a primary limiting factor for fire blight development, whereas moisture was the primary limiting factor in Israel. Brown and Sutton (6) suggested that temperature might need to be considered if the LWD-based SBFS warning system developed in the Southeast were to be applied successfully in cooler climates such as the Upper Midwest and Northeast United States. In Massachusetts, maturation of fruiting bodies of the flyspeck fungus (Schizothyrium pomi) was related to degree days (9). In contrast, temperatures in our study fell within the optimum range for mycelial growth of several common SBFS species during almost the entire fruit development period in IA and WI (15). Duration of moist periods, although gauged by RH rather than by LWD, appeared to be the limiting factor for appearance of SBFS signs in the Upper Midwest. The predictive ability of RH is not surprising, as research has shown positive correlation of both SBFS incidence and severity with hours of high RH (31).

Regional variation of SBFS species may also influence performance of weather variables as predictors of disease. Unlike the majority of warning systems, which target a single pathogen species $(7,19,27)$, the SBFS warning system encompasses a highly diverse fungal complex (2). Available evidence indicates that genera and species of SBFS fungi prevalent in the Southeast United States are different from those in the Upper Midwest $(2,10)$. Laboratory studies have shown that optimal temperature, RH, nutritional requirements, and fungicide sensitivity can vary substantially among SBFS species $(15,21,33,36)$. It is therefore possible that the ability of specific weather variables to predict disease could vary regionally with differences in the assemblage of SBFS fungi.

The ROC curve technique proved to be a useful tool for assessing performance of disease-warning systems. The technique provides an easy method to quantify both false positive and false negative errors that can be used to evaluate tradeoffs associated with warning system algorithms (17). Since economic consequences of each type of error are likely to differ substantially for high-value crops, the economic risks associated with warning systems can be assessed readily (34). Using this technique, we were able to tailor the threshold for cumulative hours of $\mathrm{RH} \geq 97 \%$ to minimize false negatives, as the costs of apple crop loss for fresh-market sales far exceed the savings from fewer fungicide applications.

By re-assessing the algorithm driving the Sutton-Brown-Hartman warning system, the present study provided insight into observed failures in implementing the system in the Upper Midwest. The warning system has potential to be further simplified; preliminary investigations indicated that eliminating the 4-h minimum for accumulating hours of $\mathrm{RH} \geq 97 \%$ made a slight but nonsignificant improvement in model accuracy (K. B. Duttweiler, unpublished data). Before the modified warning system based on cumulative hours of $\mathrm{RH} \geq$ 97\% can be recommended for grower use in the Upper Midwest, however, it must be validated in field trials over multiple sites and years.

\section{ACKNOWLEDGMENTS}

We thank Forrest W. Nutter, Jr., and S. Elwynn Taylor for helpful advice, Steven Lund for statistical assistance, Russell Spear, Elizabeth Brown, and Sam Anas for technical assistance, and Jean C. Batzer for thoughtful review of the manuscript. We are grateful to commercial apple growers in Iowa, Wisconsin, and North Carolina, whose cooperation made the study possible. Funding was provided by Grant \#IOW06656 from the Pesticide Management Alternatives Program (PMAP) of USDA.

\section{LITERATURE CITED}

1. Babadoost, M., McManus, P. S., Helland, S. N., and Gleason, M. L. 2004. Evaluating a wetness-based warning system and reducedrisk fungicides to manage sooty blotch and flyspeck of apple. HortTechnology 14:51-57.

2. Batzer, J. C., Gleason, M. L., Harrington, T. C., and Tiffany, L. H. 2005. Expansion of the sooty blotch and flyspeck complex on apples based on analysis of ribosomal DNA gene sequences and morphology. Mycologia 97:12681286.

3. Batzer, J. C., Gleason, M. L., Taylor, S. E., and Koehler, K. 2005. Impact of sensor placement in apple tree canopies on performance of a warning system for sooty blotch and flyspeck. (Abstr.) Phytopathology 95:S7.

4. Batzer, J. C., Gleason, M. L., Taylor, S. E., Koehler, K. J., and Monteiro, J. E. B. A. 2008. Spatial heterogeneity of leaf wetness duration in apple trees and its influence on performance of a warning system for sooty blotch and flyspeck. Plant Dis. 92:164-170.

5. Batzer, J. C., Gleason, M. L., Weldon, B., Dixon, P. M., and Nutter, F. W., Jr. 2002. Evaluation of postharvest removal of sooty blotch and flyspeck on apples using sodium hypochlorite, hydrogen peroxide with peroxyacetic acid, and soap. Plant Dis. 86:13251332.

6. Brown, E. M., and Sutton, T. B. 1995. An empirical model for predicting the first symptoms of sooty blotch and flyspeck of apples. Plant Dis. 79:1165-1168.

7. Campbell, C. E., and Madden, L. V. 1990. Forecasting plant diseases. Pages 423-452 in: Introduction to Plant Disease Epidemiology. C. E. Campbell and L. V. Madden, eds. John Wiley \& Sons, New York.

8. Cooley, D. R., Gamble, J. W., and Autio, W. R. 1997. Summer pruning as a method for reducing flyspeck disease on apple fruit. Plant Dis. 81:1123-1126.

9. Cooley, D. R., Lerner, S. M., and Tuttle, A. F. 2007. Maturation of thyriothecia of Schizothyrium pomi on the reservoir host Rubus allegheniensis. Plant Dis. 91:136-141.

10. Díaz, M. M., Batzer, J. C., and Gleason, M. L.
2006. Expansion of the sooty blotch and flyspeck complex on apples in the eastern U.S based on analysis of ribosomal DNA and fungal morphology. (Abstr.) Phytopathology 96:S29.

11. Gillespie, T. J., Sristava, B., and Pitblado, R. E. 1993. Using operational weather data to schedule fungicide sprays on tomato in southern Ontario. Can. J. Appl. Meteorol. 32:567573.

12. Gleason, M. L., ed. 2008. 2008 Midwest Tree Fruit Spray Guide. Bull. PM-1282, Iowa State University Extension, Ames, IA.

13. Hall, J. C., Frank, M., Tuttle, A. F., and Cooley, D. R. 1997. Can we predict flyspeck development? Fruit Notes 62:21-23.

14. Hartman, J. R. 1996. Evaluation of fungicide timing for sooty blotch and flyspeck control, 1995. Fungic. Nematicide Tests 51:6.

15. Hernandez, S. M., Batzer, J. C., Gleason, M. L., Mueller, D. S., Dixon, P. M., Best, V., and McManus, P. S. 2004. Temperature optima for mycelial growth of newly discovered fungi in the sooty blotch and flyspeck complex on apples. (Abstr.) Phytopathology 94:S41.

16. Huber, L., and Gillespie, T. J. 1992. Modeling leaf wetness in relation to plant disease epidemiology. Annu. Rev. Phytopathol. 30: 553-577.

17. Hughes, G., McRoberts, N., and Burnett, F. J. 1999. Decision-making and diagnosis in disease management. Plant Pathol. 48:147-153.

18. Kim, K. S., Taylor, S. E., and Gleason, M. L. 2004. Development and validation of a leaf wetness duration model using a fuzzy logic system. Agric. For. Meterol. 127:53-64.

19. Krause, R. A., and Massie, L. B. 1975. Predictive systems: Modern approaches to disease control. Annu. Rev. Phytopathol. 13:31-47.

20. Lau, Y. F., Gleason, M. L., Zriba, N., Taylor, S. E., and Hinz, P. N. 2000. Effect of coating, deployment angle, and compass orientation on performance of electronic wetness sensors during dew periods. Plant Dis. 84:192-197.

21. Le Corronc, F., Batzer, J. C., and Gleason, M. L. 2006. Effect of apple juice on in vitro morphology of four newly discovered fungi in the sooty blotch and flyspeck complex. (Abstr.) Phytopathology 96:S65.

22. Manly, B. F. J. 1997. Randomization, Bootstrap and Monte Carlo Methods in Biology, 2nd ed. CRC Press, USA.

23. Metz, C. E. 1978. Basic principles of ROC analysis. Semin. Nucl. Med. 8:283-298.

24. Ocamb-Basu, C. M., and Sutton, T. B. 1988. Effects of temperature and relative humidity on germination, growth, and sporulation of $Z y$ gophiala jamaicensis. Phytopathology 78:100103.

25. Rosenberger, D. A. 1997. Refining and validating a fungicide timing model for controlling flyspeck on apples in the Hudson Valley. NYS IPM Publ. 214:28-36.

26. Royle, D. J., and Butler, D. R. 1986. Epidemiological significance of liquid water in crop canopies and its role in disease forecasting. Pages 139-159 in: Water, Fungi and Plants. P. G. Ayres and L. Boddy, eds. Cambridge University Press, Cambridge.

27. Royle, D. J., and Shaw, M. W. 1988. The costs and benefits of disease forecasting in farming practice. Pages 231-246 in: Control of Plant Diseases: Costs and Benefits. B. C. Clifford and E. Lester, eds. Blackwell, Oxford.

28. Sentelhas, P. C., Gillespie, T. J., Batzer, J. C., Gleason, M. L., Monteiro, J. E., Pezzopane, J. R., and Pedro, M. J., Jr. 2005. Spatial variability of leaf wetness duration in different crop canopies. Int. J. Biometeorol. 49:363-370.

29. Shtienberg, D., Shwartz, H., Oppenheim, D., Zilberstaine, M., Herzog, Z., Manulis, S., and Kritzman, G. 2003. Evaluation of local and imported fire blight warning systems in Israel. Phytopathology 93:356-363. 
30. Smigell, C. G., and Hartman, J. R. 1997. Evaluation of fungicide timing for sooty blotch and flyspeck control, 1996. Fungic. Nematicide Tests 52:24.

31. Sutton, A. L., and Sutton, T. B. 1994. The distribution of the mycelial types of Gloeodes pomigena on apples in North Carolina and their relationship to environmental conditions. Plant Dis. 78:668-673.

32. Sutton, O. G. 1977. Micrometeorology: A study of physical processes in the lowest layers of the earth's atmosphere. R. E. Krieger, New York.

33. Tarnowski, T. L., Batzer, J. C., Gleason, M. L., Helland, S., and Dixon, P. M. 2003. Sensitivity of newly identified clades in the sooty blotch and flyspeck complex on apple to thiophanatemethyl and ziram. Online. Plant Health Progress doi:10.1094/PHP-2003-1209-01-RS.

34. Turechek, W. W., and Wilcox, W. F. 2005. Evaluating predictors of apple scab with receiver operating characteristic curve analysis.
Phytopathology 95:679-691.

35. Twengström, E., Sigvald, R., Svensson, C., and Yuen, J. E. 1998. Forecasting Sclerotinia stem rot in spring sown oilseed rape. Crop Prot. 17:405-411.

36. Williamson, S. M., and Sutton, T. B. 2000 Sooty blotch and flyspeck of apple: Etiology, biology, and control. Plant Dis. 84:714-724.

37. Yuen, J. E., and Hughes, G. 2002. Bayesian analysis of plant disease prediction. Plant Pathol. 51:407-412. 